\title{
Reliability and validity of Amharic version of EORTC QLQ-C30 and QLQ-BR23 modules for assessing health-related quality of life among breast cancer patients in Ethiopia
}

Diriba Alemayehu Gadisa ${ }^{1 *} \mathbb{B}$, Esayas Tadesse Gebremariam² and Getnet Yimer Ali $^{3}$

\begin{abstract}
Background: Breast cancer is the most common cancer among women and it affects quality of life of those women. So far, the two most frequently used tools for assessing health related quality of life in breast cancer patients, EORTC QLQ-C30 and EORTC QLQ-BR23 modules, were not validated in Ethiopia. Hence, the present study aimed to assess the psychometric properties of the tools among Ethiopian breast cancer patients.

Methods: Institutional based longitudinal study was conducted from January 1 to May 1, 2017 GC at only nationwide oncology center, Tikur Anbessa Specialized Hospital (TASH), Addis Ababa, Ethiopia. A total of 146 patients who visited the facility during that period, with no missing quality of life data, were selected for analysis. The psychometric properties of the EORTC QLQ-C30 and EORTC QLQ-BR23 were evaluated in terms of reliability, convergent, divergent, construct and clinical validity using SPSS version 22.

Results: Satisfactory internal consistency reliability (Cronbach's a coefficients $>0.7$ ) was confirmed, except for cognitive function $(a=0.516)$ of EORTC QLQ-C30 and body image $(a=0.510)$ of EORTC QLQ-BR23. Multiple-trait scaling analysis demonstrated a good convergent and divergent validity. No scaling errors were observed. Most items in EORTC QLQ-BR23 possessed a weak or no correlation with its own dimension in EORTC QLQ-C30 $(r<0.4)$ except with some of symptom scales. A statistically significant chemotherapy induced quality of life scores changes $(P \leq 0.05)$ were observed in all dimensions of both instruments between baseline and the end of first cycle chemotherapy, except for body image $(P=0.985)$ and sexual enjoyment $(P=0.817)$ of EORTC QLQ-BR23, indicating clinical validity.
\end{abstract}

Conclusion: Amharic version of the EORTC QLQ-C30 and EORTC QLQ-BR23 modules are valid and adequately reliable tool and can be used for clinical and epidemiological cancer researches to study the health related quality of life (HRQOL) of women with breast cancer in Ethiopia.

Keywords: Quality of life, Amharic, Validation, Breast cancer, Ethiopia

\footnotetext{
* Correspondence: direalexphar@ymail.com

'Lecturer of pharmacology at Pharmacy department, College of Medicine

and Health Sciences, Ambo University, Ambo, Ethiopia

Full list of author information is available at the end of the article
}

(C) The Author(s). 2019 Open Access This article is distributed under the terms of the Creative Commons Attribution 4.0 International License (http://creativecommons.org/licenses/by/4.0/), which permits unrestricted use, distribution, and reproduction in any medium, provided you give appropriate credit to the original author(s) and the source, provide a link to the Creative Commons license, and indicate if changes were made. The Creative Commons Public Domain Dedication waiver (http://creativecommons.org/publicdomain/zero/1.0/) applies to the data made available in this article, unless otherwise stated. 


\section{Background}

According to GLOBOCAN, breast cancer is the most common cancer in women, accounting for $25.1 \%$ of all cancers and associated with higher incidence and mortality in developed countries [1]. The impact of cancer on patients' lives can be measured. Health related quality of life (HRQoL) is defined as a multi-dimensional construct covering disease and treatment-related symptoms, physical, psychological, and social functioning [2, 3].

Measuring HRQoL in cancer treatments is considered as one of the major out-come parameters to measure the efficacy of the chemotherapy in addition to classical biomedical indicators [4-6] which needs reliable and validated instruments in that specific population [3, 7].

European Organization for Research and Treatment of Cancer (EORTC) developed an integrated measurement system for evaluating the quality of life of cancer patients participating in international clinical trials. It includes core European Organization for Research and Treatment of Cancer Quality of Life Questionnaire (EORTC QLQ-C30) and other supplementary modules including breast cancer specific European Organization for Research and Treatment of Cancer Quality of Life Questionnaire (EORTC QLQ-BR 23) [8]. Health related quality of life questionnaire in patients with breast cancer, EORTC QLQ-C30 and EORTC QLQ-BR23, have been developed in English-speaking countries. As a result, its cross socio-cultural and linguistic reliability and validity should be determined for population outside Europe [3, 9, 10]. These measuring instruments have also been translated into different languages world-wide with the support of cross-cultural validation [3].

The only reliability and validity study conducted on the Amharic version of EORTC QLQ-C30 was in gynecological cancer patients by Ayana et al. [11], and this is the first study to asses that among breast cancer patients, in Ethiopia. The earlier study also lacks the inclusion of a construct validity test with other instruments and clinical validity in terms of changes or responsiveness of instruments to clinical changes over a time. Moreover, Amharic version EORTC QLQ-C30 and EORTC QLQ-BR23 questionnaires were not validated for women with breast cancer in Ethiopia though it was previously translated into Amharic [12, 13]. Consequently, the aim of this study is to validate the translated Amharic version of EORTC QLQ-C30 and EORTC QLQ-BR23 in Ethiopian women with breast cancer using a more reliable and informative study design.

\section{Methods and patients}

The institutional based longitudinal study was conducted from January 1 to May 1, 2017 GC at the one and only nationwide oncology center, Tikur Anbessa Specialized Hospital (TASH), Addis Ababa, Ethiopia. We used two time periods (i.e., at baseline and on $21^{\text {st }}$ day of first cycle chemotherapy) and enrolled all the146 patients visited the facility, with no missing quality of life data. A sample size of 100 patients is considered to have enough power to evaluate quality of life study for each specific cancer site [14].Women age above 18 years with proven newly diagnosed breast cancer from stage I to IV and scheduled to receive the most commonly used neo/adjuvant or palliative first line chemotherapy (i.e., Adriamycin-Cyclophosphamide [AC] and AdriamycinCyclophosphamide followed by Paclitaxel [AC-T] regimen) were included.

We excluded patients who had previous history of breast cancer treatment (i.e. currently on second line for recurrent breast cancer). Patients with psychiatric disorders, other severe medical illnesses and incomplete quality of life data were also excluded from analysis.

The translation of the EORTC QLQ-C30 and QLQBR23 into Amharic version was made considering detailed procedures documented in EORTC Quality of Life Group manual [12, 13, 15]. This study had received the translated Amharic EORTC QLQ-C30 and QLQ-BR23 version from EORTC with permission to use for the proposed study.

Sharp et al. showed that the mode of administering EORTC QLQ-C30 and EORTC QLQ-BR23 questionnaires, whether via interview or self-administration, does not interfere with the scores reported by patients [16]. Unfortunately, in our study, most of the patients had no basic education or had only primary school education, making self-administration of the questionnaire difficult. As a result, all of the study participants were interviewed. Paper based Amharic versions of the EORTC QLQ-C30 and EORTC QLQ-BR23 module were read out loud for patients in a private room by trained oncology nurses. The first interview was made on the same day of their first cycle chemotherapy (i.e., before initiating chemotherapy) whereas the second interview was on first day of their second cycle chemotherapy (i.e., on $21^{\text {st }}$ day) for all patients.

Item scores of the EORTC QLQ-C30 and EORTC QLQ-BR23 were managed according to the EORTC QLQ-C30 scoring manual. After the scoring procedures, all scale and single-item scores were linearly transformed to a $0-100$ scale. Higher scores for functional scales and the global quality of life scale, indicate 'higher level of functioning or global quality of life', while for symptom scales and single items, a higher score indicates a 'higher level of symptoms or problems' [15].

\section{Statistical analysis}

The Statistical Package for Social Sciences (IBM Corp. Released 2013. IBM SPSS Statistics for Windows, Version 22.0, Armon, NY: IBM Corp.) Software was used for analysis. Accordingly, categorical and continuous 
Table 1 Socio-demographic data of women with breast cancer at TASH, from January 1 to May 1, 2017 GC, N=146

\begin{tabular}{|c|c|c|c|c|c|}
\hline Category & N (\%) & Mean \pm SD & Category & N (\%) & Mean \pm SD \\
\hline \multicolumn{3}{|l|}{ Age(Year) } & III & \multicolumn{2}{|l|}{$64(43.83)$} \\
\hline $20-34$ & $30(20.50)$ & \multirow[t]{4}{*}{$42.24 \pm 11.50$} & IV & \multicolumn{2}{|l|}{ 28(19.17) } \\
\hline $35-49$ & $76(52.10)$ & & \multicolumn{3}{|c|}{ Co morbidity } \\
\hline $50-64$ & $31(21.20)$ & & Yes & $22(15.07)$ & \\
\hline$\geq 65$ & $9(6.20)$ & & No & 124(84.93) & \\
\hline \multicolumn{3}{|c|}{ Body Mass Index(BMI)(Kgm $\left.{ }^{-2}\right)$} & \multicolumn{3}{|c|}{ ECOG Performance status } \\
\hline$<18.50$ & $14(9.60)$ & \multirow[t]{4}{*}{$25.22 \pm 10.35$} & 0 & $3(2.05)$ & \\
\hline $18.5-24.99$ & $74(50.70)$ & & । & 135(92.46) & \\
\hline $25-29.99$ & $30(23.30)$ & & $\|$ & $5(3.42)$ & \\
\hline$\geq 30$ & $24(16.40)$ & & III & $3(2.05)$ & \\
\hline
\end{tabular}

Marital status

Married

98(67.10)

Widowed

20(13.70)

Divorced

18(12.30)

Single

10(6.80)

Children

Having child
Having no child

Occupational status

House wife

Employed

Farmer

Merchant

Daily worker

Educational status

Up to grade 12

|lliterate

Diploma

Degree

115(78.80)

$31(21.20)$

86(58.90)

27(18.50)

13(8.90)

13(8.90)

7(4.80)

63(43.20)

58(39.70)

15(10.30)

10(6.80)

Religion

Orthodox

98(67.10)

Muslim

34(23.30)

Protestant

14(9.60)

Histological classification

$\begin{array}{ll}\text { Ductal } & 131(89.73) \\ \text { Lobular } & 6(4.11) \\ \text { Mixed } & 3(2.05) \\ \text { Papillary } & 3(2.05) \\ \text { Mucinous } & 2(1.37) \\ \text { Metaplastic } & 1(0.68) \\ \text { Stage } & \\ \text { I } & 6(4.11) \\ \text { II } & 48(32.87)\end{array}$

Table 1 Socio-demographic data of women with breast cancer at TASH, from January 1 to May 1, 2017 GC, N=146 (Continued)

variables were expressed with frequencies and percentages, and means and standard deviations, respectively.

The psychometric properties of the EORTC QLQC30 and EORTC QLQ-BR23 were evaluated in terms of reliability, convergent, divergent, construct and clinical validity test. Reliability (internal consistency) of the questionnaire was tested by Cronbach's alpha coefficient and the acceptable value to be met was $\geq 0.70$ [8]. Multi-trait scaling analysis was used for item convergent and divergent or discriminant validity. Convergent validity was predicted if the correlation value of an item and its own scale was $\geq 0.40$ and divergent validity if the correlation of an item with its own scale was higher than with other scales. And for clinical validity, quality of life score change over a time was used $[8,17]$. As a result, repeated measure ANOVA was used to detect whether there is significant quality of life score change $(P \leq 0.05)$ over a time or not. And a definite scaling success was assumed if the correlation of an item with its own exceeded correlation with other scales [4].

Construct validity was evaluated under the hypothesis that the EORTC QLQ-C30 subscales and EORTC QLQBR23 subscales were correlated with each other (acceptable correlation coefficients were $\geq 0.40$ ) [18].

\section{Ethical issues}

The study was approved by Institutional Review Board (IRB) of the school of pharmacy, Collegeof Health Sciences, Addis Ababa University (Ref No:ERB/SOP/09/ 2016). Informed consent was obtained from all patients prior to participation in the study.

\section{Results}

Socio-demographic characteristics of the study participants

Among the study participants $98(67.10 \%)$ were married, $115(78.80 \%)$ had at least one child, $86(58.90 \%)$ were 
house wife, 58(39.70\%) were illiterate, and 98(67.10\%) were Orthodox. 42.24 years and $25.22 \mathrm{Kgm}^{-2}$ were the mean age and body mass index of the study participants respectively. Majority 131(89.73\%) had ductal carcinoma and 135 (92.46\%) had Eastern Cooperative Oncology Group (ECOG) performance I (Table 1).

ECOG European Cooperative Oncology Group, SD Standard Deviation

\section{Reliability test}

Table 2 showed that, except for cognitive $(\alpha=0.516)$ and body image $(\alpha=0.510)$ scales, all scales had Cronbach's $\alpha$ coefficients above the acceptable level of 0.70 .

\section{Validity test}

All item-scale correlation coefficients were above 0.40 , except for hair loss which is 0.337 , supporting an item convergent validity. Furthermore, the magnitude of the correlation of each item with its own scale exceeded the

Table 2 Reliability of EORTC QLQ-C30 and QLQ-BR23 Amharic version in women with breast cancer in Ethiopia $(n=146)$

\begin{tabular}{|c|c|c|}
\hline EORTC & Scales & Cronbach's a value \\
\hline \multirow[t]{15}{*}{ QLQ-C30 } & Global Health status/QoL & 0.789 \\
\hline & Physical functioning & 0.771 \\
\hline & Role functioning & 0.908 \\
\hline & Emotional functioning & 0.817 \\
\hline & Cognitive functioning & 0.516 \\
\hline & Social functioning & 0.779 \\
\hline & Fatigue & 0.851 \\
\hline & Nausea and vomiting & 0.857 \\
\hline & Pain & 0.739 \\
\hline & Dyspnea & Single item \\
\hline & Insomnia & Single item \\
\hline & Appetite loss & Single item \\
\hline & Constipation & Single item \\
\hline & Diarrhea & Single item \\
\hline & Financial difficulties & Single item \\
\hline \multirow[t]{8}{*}{ QLQ-BR23 } & Body image & 0.510 \\
\hline & Sexual functioning & 0.962 \\
\hline & Systemic therapy side effects & 0.755 \\
\hline & Breast symptoms & 0.773 \\
\hline & Arm symptoms & 0.749 \\
\hline & Sexual enjoyment & Single item \\
\hline & Future perspective & Single item \\
\hline & Upset by hair loss & Single item \\
\hline
\end{tabular}

${ }^{\mathrm{a}}$ For single items, reliability test is not applicable. EORTC QLQ-C30 and QLQBR23 = European Organization for Research and Treatment of Cancer Quality of Life Questionnaire-Core 30 (QLQ-C30) and Breast Cancer specific (QLQBR23) questionnaire. QoL = Quality of Life correlation with another scale and hence it met divergent validity and scaling success (Table 3 ).

\section{Construct validity}

Global Health scale and pain scale were more correlated to symptoms scales of EORTC QLQ-BR23 $(r=0.472-$ 0.553). Fatigue, emotional functioning and cognitive function were moderately correlated with systemic therapy side effects EORTC QLQ-BR23 ( $\mathrm{r}=0.405-0.633)$. Out of 45 possible correlations among the scales both questionnaires, 38 were correlated at least at $P \leq 0.05$ (Table 4).

\section{Clinical validity}

Repeated measures ANOVA showed all EORTC QLQC30 scales changed significantly over a time $(P<0.05)$. It also showed significant change of EORTC QLQ-BR23 over a time except for body image and sexual enjoyment. And all significant changes were towards expected direction (Table 5).

\section{Discussions}

Health-related quality of life is considered as an important endpoint in cancer clinical trials [2]. There is a need to complement conventional clinical outcomes with information representing the patients' perception of outcome. A better understanding of HRQoL may lead to enhanced care of patients with cancer [17].

The measurement of patient-reported outcomes, including health-related quality of life, with reliable and valid tools and its incorporation into clinical practice for breast cancer patients have paramount advantages $[2,7]$. EORTC QLQ-C30 HRQoL scales provide valuable prognostic information when combined with socio-demographic and clinical information [3].

Our study showed that Amharic version EORTC QLQ-C30 instrument was reliable as the value for internal consistency ranges from $0.739-0.908$ except for cognitive domain $(\alpha=0.516)$ which had Cronbach's alpha value $\leq 0.7$. Different studies in different parts of the world, Albanian $(\alpha=0.54)$ [18], Taiwan $(\alpha=0.54)$ [19], Thailand $(\alpha=0.50)$ [4], Arabic $(\alpha=0.67)$ [10], Amharic version in gynecological cancer in Ethiopian $(\alpha=0.29)$ [11], Mexican-Spanish $(\alpha=0.52)$ [17], Moroccan $(\alpha=0.34)$ [5], Singapore $(\alpha=0.19)$ and others reviewed by Luo et al. [20] showed as cognitive functioning did not meet the internal consistency standards.

From EORTC QLQ-BR23, body image showed minimum internal consistency $(\alpha=0.510)$ which was below the minimum requirements $(\alpha \leq 0.7)$ in contrast to systemic side effects among Iranian patients $(\alpha=0.63)$ [9]. However, other scales showed good internal consistency which ranges from 0.749-0.962. Our 
Table 3 Multi-trait scale analysis for convergent and divergent validity of EORTC QLQ-C30 and QLQ-BR23 Amharic version in women with breast cancer in Ethiopia $(n=146)$

\begin{tabular}{|c|c|c|c|c|}
\hline \multicolumn{2}{|l|}{ EORTC QLQ-C30 } & \multirow{2}{*}{$\begin{array}{l}\text { Item-own scale } \\
\text { correlations }^{b}\end{array}$} & \multirow{2}{*}{$\begin{array}{l}\text { Item-other } \\
\text { scale } \\
\text { correlations }^{\text {b }}\end{array}$} & \multirow{2}{*}{$\begin{array}{l}\text { Scaling } \\
\text { success }\end{array}$} \\
\hline Scale & Sub-scale & & & \\
\hline \multirow[t]{3}{*}{ Overall Quality of life } & Global Health Status & $0.887-0.909$ & $0.091-0.589$ & $2 / 2$ \\
\hline & Physical & $0.442-0.870$ & $0.013-0.572$ & $5 / 5$ \\
\hline & Role & $0.958-0.959$ & $0.12-0.639$ & $2 / 2$ \\
\hline \multirow[t]{3}{*}{ Functional scales } & Emotional & $0.647-0.838$ & $0.008-0.582$ & $4 / 4$ \\
\hline & Cognitive & $0.753-0.800$ & $0.025-0.487$ & $2 / 2$ \\
\hline & Social & $0.874-0.898$ & $0.041-0.439$ & $2 / 2$ \\
\hline \multirow[t]{3}{*}{ Symptoms scales } & Fatigue & $0.830-0.880$ & $0.164-0.629$ & $3 / 3$ \\
\hline & Nausea and vomiting & 0.769-0.999 & $0.029-0.377$ & $2 / 2$ \\
\hline & Pain & $0.870-0.892$ & $0.116-0.634$ & $2 / 2$ \\
\hline \multicolumn{5}{|l|}{ EORTC QLQ-BR23 } \\
\hline \multirow[t]{2}{*}{ Functional scales } & Body Image & $0.695-0.854$ & $0.026-0.384$ & $4 / 4$ \\
\hline & Sexual functioning & $0.961-0.969$ & $0.005-0.029$ & $2 / 2$ \\
\hline \multirow[t]{3}{*}{ Symptoms scales } & Therapy's side effects $^{a}$ & $0.337-0.7880 .636-0.800$ & $0.006-0.534$ & $7 / 7$ \\
\hline & Breast symptoms & & $0.009-0.636$ & $4 / 4$ \\
\hline & Arm symptoms & $0.604-0.856$ & $0.031-0.614$ & $3 / 3$ \\
\hline
\end{tabular}

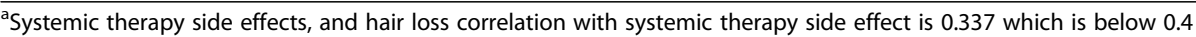

bspearman correlation coefficients

study, however, showed the lower internal consistency value compared with the Spanish breast cancer patients (0.46-0.94) while it was higher when compared with the result from the American and Dutch breast cancer patients $(0.57-0.91)$ [21]. Role functioning $(\alpha=$ $0.908)$, nausea and vomiting $(\alpha=0.857)$ and fatigue $(\alpha=0.851)$ from EORTC QLQ-C30 and sexual functioning $(\alpha=0.962)$ from EORTC QLQ-BR23 showed strong internal consistency. The Brazilian version also showed higher scores in both instruments $(\alpha=0.72-$ 0.86) [22].
In our study, multi-trait scaling analysis showed that almost all of items had strong correlations with their respective sub-scale $(r \geq 0.6)$ that indicates a strong convergent validity of the instruments [17], with the exception of hair loss to systemic therapy side effects. There was no scaling error found as all of the items of both instruments discriminate significantly between their own and other domains indicating divergent validity. This is in contrast to previous study in patients with gynecological cancer for EORTC QLQ-C30 [11]. Our study was consistent with different studies conducted

Table 4 Construct validity of EORTC QLQ-C30 Amharic version with its supplementary EORTC QLQ-BR23 scales in women with breast cancer in Ethiopia $(n=146)$

\begin{tabular}{|c|c|c|c|c|c|}
\hline \multicolumn{6}{|c|}{ Spearman's correlation coefficients } \\
\hline & Body image & Sexual Functioning & Therapy side effects & Breast symptoms & Arm symptoms \\
\hline Physical functioning & $.224^{a}$ & $.174^{\mathrm{b}}$ & $-.362^{a}$ & $-.208^{b}$ & $-.329^{a}$ \\
\hline Role functioning & 0.086 & $.198^{\mathrm{b}}$ & $-.264^{\mathrm{a}}$ & -0.14 & $-.225^{\mathrm{a}}$ \\
\hline Emotional functioning & $.394^{\mathrm{a}}$ & 0.064 & $-.471^{\mathrm{a}}$ & $-.294^{\mathrm{a}}$ & $-.328^{\mathrm{a}}$ \\
\hline Cognitive functioning & $.408^{\mathrm{a}}$ & 0.125 & $-.405^{\mathrm{a}}$ & $-.177^{b}$ & $-.261^{\mathrm{a}}$ \\
\hline Social functioning & $.323^{a}$ & $.183^{\mathrm{b}}$ & $-.266^{\mathrm{a}}$ & $-.216^{\mathrm{a}}$ & $-.228^{\mathrm{a}}$ \\
\hline Fatigue & $-.354^{\mathrm{a}}$ & $-.245^{\mathrm{a}}$ & $.633^{\mathrm{a}}$ & $.376^{a}$ & $.424^{\mathrm{a}}$ \\
\hline Nausea and vomiting & $-.197^{b}$ & 0.005 & $.302^{\mathrm{a}}$ & $.186^{\mathrm{b}}$ & $.262^{\mathrm{a}}$ \\
\hline Pain & $-.214^{\mathrm{a}}$ & -0.06 & $.516^{\mathrm{a}}$ & $.456^{\mathrm{a}}$ & $.495^{\mathrm{a}}$ \\
\hline Global Health score & $.387^{\mathrm{a}}$ & 0.15 & $-.553^{\mathrm{a}}$ & $-.472^{\mathrm{a}}$ & $-.484^{\mathrm{a}}$ \\
\hline
\end{tabular}

${ }^{a}$ Correlation is significant at the 0.01 level (2-tailed)

${ }^{b}$ Correlation is significant at the 0.05 level (2-tailed)

The bold entries indicate those sub-scales having spearman's correlation coefficients $\geq 0.40$ 
Table 5 Clinical validity EORTC QLQ-C30 and QLQ-BR23 Amharic version in women with breast cancer in Ethiopia $(n=146)$

\begin{tabular}{|c|c|c|c|c|}
\hline \multicolumn{5}{|c|}{ Quality of life score: mean(SD) } \\
\hline & EORTC-QLQ-C30 & Baseline & End of $1 \mathrm{st} C \mathrm{~T}^{\mathrm{b}}$ cycle & $\overline{p \text {-value }}$ \\
\hline \multirow[t]{3}{*}{ Overall QoL } & Global Health status & $57.36(20.09)$ & $41.72(19.24)$ & 0.000 \\
\hline & Physical & $68.63(26.06)$ & $51.00(23.70)$ & 0.000 \\
\hline & Role & $52.74(38.85)$ & 23.74(31.37) & 0.000 \\
\hline \multirow[t]{4}{*}{ Functional scales } & Emotional & $80.02(22.60)$ & $67.81(25.14)$ & 0.000 \\
\hline & Cognitive & $86.41(19.96)$ & $77.39(26.31)$ & 0.000 \\
\hline & Social & $74.88(30.59)$ & $58.22(33.11)$ & 0.000 \\
\hline & Fatigue & 28.69(30.40) & $72.07(26.10)$ & 0.000 \\
\hline \multirow[t]{4}{*}{ Symptoms scales } & Nausea and Vomiting & $3.31(11.84)$ & $53.53(34.19)$ & 0.000 \\
\hline & Pain & $32.53(30.53)$ & $42.00(33.11)$ & 0.001 \\
\hline & Dyspnea & $19.40(29.75)$ & $28.76(29.97)$ & 0.003 \\
\hline & Insomnia & $27.85(34.58)$ & $35.61(37.88)$ & 0.024 \\
\hline \multirow[t]{4}{*}{ Single items } & Appetite loss & $17.80(29.59)$ & $71.23(31.22)$ & 0.000 \\
\hline & Constipation & $10.27(21.99)$ & 22.83(31.74) & 0.000 \\
\hline & Diarrhea & $2.74(12.07)$ & 16.89(30.38) & 0.000 \\
\hline & Financial problem & $61.18(36.72)$ & $65.52(33.77)$ & 0.000 \\
\hline \multicolumn{5}{|l|}{ EORTC-QLQ-BR23 } \\
\hline \multirow[t]{3}{*}{ Functional scales } & Body Image & $72.54(42.45)$ & $72.60(27.24)$ & 0.985 \\
\hline & Sexual Functioning & $21.11(36.95)$ & $12.21(28.72)$ & 0.004 \\
\hline & Therapy $^{a}$ side effects & $12.88(15.08)$ & $50.71(19.70)$ & 0.000 \\
\hline \multirow[t]{2}{*}{ Symptoms scale } & Breast symptoms & $22.48(22.34)$ & 17.63(19.94) & 0.000 \\
\hline & Arm symptoms & 26.03(26.08) & 18.79(23.18) & 0.000 \\
\hline \multirow[t]{2}{*}{ Single items } & Future perspectives & 69.63(33.43) & $63.69(35.21)$ & 0.041 \\
\hline & Sexual Enjoyment & $72.91(32.70)$ & 70.83(34.15) & 0.817 \\
\hline
\end{tabular}

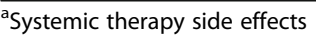

${ }^{\mathrm{b}}$ After three weeks, on $21^{\text {st }}$ day of the CT (Chemotherapy) or on the first day of $2^{\text {nd }}$ cycle CT.

SD Standard Deviation, QoL Quality of Life

elsewhere $[5,10,20,23]$. As a result, the translated Amharic version EORTC QLQ-C30 [13] and EOTRC QLQBR23 [12] were psychometrically valid in Ethiopian women with breast cancer.

There were strong correlations $(r=0.405-0.633)$ between systemic therapy side effects of EORTC QLQ-BR23 and emotional, cognitive, fatigue, pain and global health status of EORTC QLQ-C30. Arm symptoms also showed strong correlations $(r=0.424-0.495)$ with fatigue, global health status and pain whereas breast symptoms showed moderate correlations with pain and global health status. This implies that symptom scales of EORTC QLQ-BR23 were more correlated with the corresponding scales of EORTC QLQ-C30 than the functional scales. Furthermore, our study showed significant correlations $(P \leq 0.05)$ between the two instruments' scales but the majority showed weak $(r<0.4)$ or no significant correlations, in particular sexual functioning, with other domains. Weak or no correlation indicates the EORTC QLQ-BR23 has unique domains of HRQoL, which are not addressed by the EORTC QLQ-C30. As a result, this finding further strengthens as EORTC QLQ-BR23 only used with EORTC QLQ C-30 [21] to assess the HRQoL of breast cancer patients in different way to EORTC QLQ-C30.

Health-related quality of life is a dynamic multidimensional measurement that changes over time and within the same patient [17]. Likewise, except for body image $(P=0.985)$ and sexual enjoyment $(P=0.817)$ of EORTC QLQ-BR23, all sub-scales and single items of EORTC QLQ-C30 and EORTC QLQ-BR23 quality of life scores showed significant chemotherapy induced changes $(P \leq 0.05)$ between pretreatment and on $21^{\text {st }}$ day of first cycle chemotherapy. The changes were towards the expected direction. Functional and Global quality of life domains scores were decreased while the symptom scales were increased. These indicates deterioration of quality of life from the baseline [15]. Hence, both questionnaires effectively discriminate quality of life scores at different point in a time which ensures clinical validity of the instruments. 
Our study also had some limitations as we didn't manage to measure test-retest reliability of the EORTC QLQ-C30 and EORTC QLQ-BR23. And we didn't check the external convergent validity, the gold standard test to assess validity, due mainly to unavailability of other validated HRQoL assessment tool. We have tried to overcome those limitations by checking construct validity and responsiveness of both instruments over a time.

\section{Conclusions}

In general, the translated Amharic version of EORTC QLQ-C30 and EORTC QLQ-BR23 met satisfactory reliability standards, and convergent, divergent, construct and clinical validity to be used both in research and clinical as a measure of treatment out-come with respect to quality of life in women with breast cancer in Ethiopia.

\begin{abstract}
Abbreviations
ECOG: European Cooperative Oncology Group; EORTC QLQ-BR23: European Organization for Research and Treatment of Cancer Quality of Life Questionnaire breast cancer specific module; EORTC QLQ-C30: European Organization for Research and Treatment of Cancer Quality of life Questionnaire version 3; HRQoL: Health Related Quality of life; TASH: Tikur Anbessa Specialized Hospital
\end{abstract}

\section{Acknowledgments}

We would like to extend our sincere thanks to all study participants and Addis Ababa University (TASH) oncology center for their cooperation. We also acknowledge EORTC quality of life department for their permission to use their translated Amharic version EORTC QLQ-C30 and QLQ-BR23.

\section{Authors' contributions}

DAG conceived the research idea, collected the data and performed data analysis and interpretation. DAG also wrote the manuscript. GYA reviewed and edited the manuscript. All authors critically reviewed the final version of the manuscript. All authors read and approved the final manuscript.

\section{Funding}

The study was not funded by any organization.

\section{Availability of data and materials}

Please contact the first author for data requests.

\section{Ethics approval and consent to participate}

All procedures performed in studies involving human participants were in accordance with the ethical standards of the Human Research Ethics Committee or Institutional Review Board of school of pharmacy, College of Health Sciences, Addis Ababa University (Ref No:ERB/SOP/09/2016), Ethiopia. Informed consent was obtained from all individual participants prior to participation in the study.

\section{Consent for publication}

Not applicable.

\section{Competing interests}

The authors declare that they have no competing interests.

\section{Author details}

${ }^{1}$ Lecturer of pharmacology at Pharmacy department, College of Medicine and Health Sciences, Ambo University, Ambo, Ethiopia. ${ }^{2}$ Lecturer of pharmacoepidemiology and social pharmacy at Pharmacy department, College of Medicine and Health Sciences, Ambo University, Ambo, Ethiopia. ${ }^{3}$ Global One Health initiative, Office of International Affairs, The Ohio State University, Columbus, Ohio, USA.
Received: 26 July 2019 Accepted: 4 December 2019

Published online: 12 December 2019

\section{References}

1. GLOBOCAN. Global Cancer Statistics 2018: GLOBOCAN Estimates of Incidence and Mortality Worldwide for 36 Cancers in 185 Countries; 2018. https://doi.org/10.3322/caac.21492.

2. Osoba D. Health-related quality of life and cancer clinical trials. Ther Adv Med Oncol. 2011:3(2):57-71.

3. Velikova G, Coens C, Efficace F, Greimel E, Groenvold M, Johnson C, et al. Health-related quality of life in EORTC clinical trials - 30 years of progress from methodological developments to making a real impact on oncology practice. Eur J Cancer. 2012;10(1):141-9.

4. Silpakit C, Sirilerttrakul S, Jirajarus M, Thitiya Sirisinha ES, Ratanatharathorn V. The European Organization for Research and Treatment of Cancer quality of life questionnaire (EORTC QLQ-C30): validation study of the Thai version Qual Life Res. 2006;15(1):167-72.

5. Nejjari C, El Fakir S, Bendahhou K, El Rhazi K, Abda N, Zidouh A, et al. Translation and validation of European organization for research and treatment of cancer quality of life questionnaire -C30 into Moroccan version for cancer patients in Morocco. BMC Res Notes. 2014;7:228.

6. Niu H, Niu C, Wang J, Zhang Y, He P. Health-related quality of life in women with breast Cancer : a literature-based review of psychometric properties of breast cancer-specific measures. Asian Pac J Cancer Prev. 2014;15(8):3533-6.

7. Perry S, Kowalski TL, Chang C. Quality of life assessment in women with breast cancer : benefits, acceptability and utilization. Health Qual Life Outcomes. 2007:5:24.

8. Aaronson NK, te Velde A, Hopwood P, Muller M, Franklin J, Arraras Jl, et al. The European Organization for Research and Treatment of Cancer breast cancer-specific quality-of-life questionnaire module: first results from a three-country field study. J Clin Oncol. 1996;14(10):2756-68.

9. Montazeri A, Harirchi I, Vahdani M, Khaleghi F, Jarvandi S, Ebrahimi M, et al. The EORTC breast cancer-specific quality of life questionnaire (EORTC QLQBR23): translation and validation study of the Iranian version. Qual Life Res. 2000:9:177-84

10. Awad MA, Denic S, El Taji H. Validation of the European Organization for Research and Treatment of Cancer quality of life questionnaires for Arabicspeaking populations. Annals NY Acad Sci. 2008;1138:146-54.

11. Ayana BA, Negash S, Yusuf L, Tigeneh W. Reliability and validity of Amharic version of EORTC QLQ-C 30 questionnaire among gynecological Cancer patients in Ethiopia. PLoS One. 2016;11(6):1-10.

12. EORTC. EORTC QLQ-BR23 (version 1). EORTC Study Group on Quality of Life 1994 https://qol.eortc.org. Accessed 20 Jan. 2017.

13. EORTC. EORTC QLQ-C30(Version 3). EORTC Study Group on Quality of Life. 1995 https://qol.eortc.org. Accessed 20 Jan. 2017.

14. Scott NW, Fayers PM, Aaronson NK, De Graeff A, Groenvold M, Koller M, et al. EORTC QLQ-C30 reference values. Brussels: EORTC Quality of Life Group; 2008.

15. Fayers P, Aaronson N, Bjordal K, Groenvold M, Curran D, Bottomley A, et al. EORTC QLQ-C30 scoring manual. 3rd ed. Brussels: EORTC; 2001.

16. Sharp LK, Knight SJ, Nadler R, Albers M, Moran E, Kuzel T, et al. Quality of life in low-income patients with metastatic prostate Cancer : divergent and convergent validity of three instruments. Qual Life Res. 1999;8(5):461-70.

17. Cerezo O, Oñate-Ocaña LF, Arrieta-Joffe P, González-Lara F, García-Pasquel

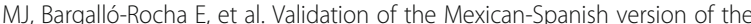
EORTC QLQ-C30 and BR23 questionnaires to assess health-related quality of life in Mexican women with breast cancer. Eur J Cancer Care. 2012;21(5): 684-91

18. Shuleta-Qehaja S, Sterjev Z, Shuturkova L. Valuation of reliability and validity of the european organization for research and treatment of cancer quality of life questionnaire (EORTC QLQ-C30, Albanian version) among breast cancer patients from Kosovo. Patient Prefer Adherence. 2015;9:459-65.

19. Huang C-C, Tu S-H, Lien H-H, Huang C-S, Wang P-C, Chie W-C. Conceptual structure of the Taiwan Chinese version of the EORTC QLQ-C30. Qual Life Res. 2015. https://doi.org/10.1007/s11136-014-0913-3.

20. Luo N, Fones CSL, Lim SE, Xie F, Thumboo J, Li SC. The European Organization for Research and Treatment of Cancer Quality of Life Questionnaire ( EORTC QLQ-C30 ): Validation of English version in Singapore. Qual Life Res. 2005;14:1181-6.

21. Sprangers BM, Groenvold M, Arraras Jl, Franklin J, Velde A, Muller M, et al. The European Organization for Research and Treatment of Cancer breast 
Cancer-specific quality-of-life questionnaire module : first results from a three-country field study. J Clin Oncol. 1996;14(10):2756-68.

22. Michels FAS, Latorre Mdo R, Maciel Mdo S. Validity, reliability and understanding of the EORTC-C30 and EORTC-BR23, quality of life questionnaires specific for breast cancer. Rev Bras Epidemiol. 2013;16(2): 352-63.

23. Tan ML, Idris DB, Teo LW, Loh SY, Seow GC. Validation of EORTC QLQ-C30 and QLQ-BR23 questionnaires in the measurement of quality of life of breast cancer patients in Singapore. Asia Pac J Oncol Nurs. 2014;1 (1):22-32.

\section{Publisher's Note}

Springer Nature remains neutral with regard to jurisdictional claims in published maps and institutional affiliations.

Ready to submit your research? Choose BMC and benefit from:

- fast, convenient online submission

- thorough peer review by experienced researchers in your field

- rapid publication on acceptance

- support for research data, including large and complex data types

- gold Open Access which fosters wider collaboration and increased citations

- maximum visibility for your research: over $100 \mathrm{M}$ website views per year

At $\mathrm{BMC}$, research is always in progress.

Learn more biomedcentral.com/submissions 